\title{
External Influences on English: From Its Beginnings to the Renaissance. D. Gary Miller. Oxford: Oxford University Press, 2012. 252 pp. ISBN: 9780199654260
}

\author{
Maria Volkonskaya \\ National Research University Higher School of Economics \\ Correspondence concerning this article should be addressed to Maria Volkonskaya, National Research \\ University Higher School of Economics, M. Pionerskaya, 12, Moscow, Russian Federation, 115054. \\ E-mail: mvolkonskaya@hse.ru
}

It is commonly known that contact is a major factor that can influence the structure of the languages involved, yet there is still disagreement on the type of outcome produced by language contact. While sociolinguists assume that it leads to simplification, linguistic typologists believe that contact induces complexification. Trying to solve this puzzle, recent research (Trudgill, 2010a, 2010b, 2011) has shown that both schools of linguistics are, in fact, correct: the type of outcome depends on the contact scenario which has taken place. Peter Trudgill maintains that one needs to distinguish between adult second-language acquisition and continuing contact leading to child bilingualism. The former results in simplification, whereas the latter brings about complexification. This claim has become the starting point for D. Gary Miller's monograph.

As stated in the preface (p. $x$ ), throughout the book Miller employs the framework of Trudgill to analyze the history of English as a contact language, discussing its external influences and, thus, complementing the existing internal studies. Within this framework, the author's main focus is on "the constituent ingredients of contemporary English" (p. x) from its beginnings up to the end of the Renaissance. To this end, he examines the influence of Celtic, Latin and Greek (early and later), Scandinavian, and French on English lexis, phonology, morphology, and syntax, providing a variety of examples and detailed case studies to illustrate the point at issue. The eight chapters that follow are mostly organized chronologically.

In the introduction (Chapter 1) Miller situates English within the Indo-European and Germanic families. He briefly describes the main constituents of Germanic and Celtic, giving numerous examples of borrowings from North Germanic, Continental

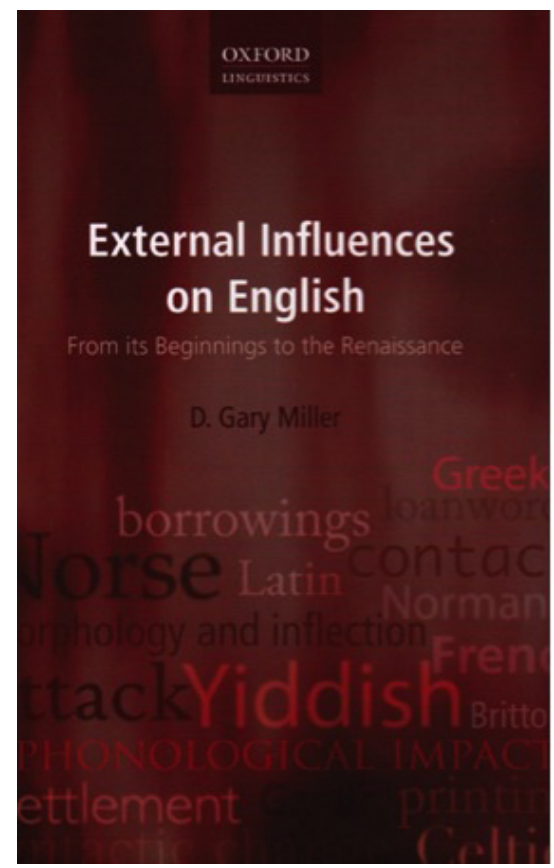

Germanic, Insular and Continental Celtic into the English language. The majority of these loanwords, however, is relatively recent and often fulfills a terminological function, such as fjord (1674) from Norwegian (p. 5), pumpernickel (1738) and shiksa (1892) from German and Yiddish respectively (p. 7), or banshee (1771) from Irish (p. 11).

Chapter 2 reviews the Celtic, Roman, and Germanic background of English. Miller starts by discussing the genetic evidence for the pre-Celts, the subsequent Celtic settlement of the British Isles and its mark on place names and other loanwords in English. Next, several periods of contact with the Romans and the 
influence of Latin both on the British Celts and the early Germanic tribes are mentioned, though the latter is described in detail in Chapter 4. In the following sections Miller discusses the arrival of the pre-English tribes in c. 5 and provides linguistic and archeological evidence for the survival of Celtic population in many areas around England after the Anglo-Saxon settlement. He argues that "the initial contacts between Celts and speakers of pre-Old English were based on equality" (p.40), resulting in complexification. Miller claims that the two Old English paradigms of to be, it-clefts and the English aspect system are all examples of this development. The enslavement of Brittonic women by the invading Germanic tribes and the following language shift, on the other hand, led to simplification, as "in [slave] communities... children would not have been exposed to Brittonic but would have learned the imperfectly acquired (non-native) English from their mothers and/or the female slaves as their first language" (p. 40). According to Miller, these morphosyntactic simplifications became manifest in Middle English.

Chapter 3, entitled "English: The early period", provides a short overview of the main events of the external history of English from c. 6 to c. 10-11. Although this chapter somewhat overlaps with the previous one, its main focus is shifted towards Latin influences. Miller emphasizes the importance of Christianization for the English language, as it resulted both in the several layers of Christian borrowings and a revival of Roman culture, the Roman alphabet, and the use of Latin.

Continuing the previous discussion, Chapter 4 is a careful study of early English loanwords from Latin and Greek. This chapter falls into two parts. In the first part Miller discusses the dating of loanwords on the basis of their phonological shape and gives a brief outline of sound changes (a) from Latin to Romance and (b) from West Germanic to Old English. The second part of this chapter is a comprehensive chronological list of old English borrowings arranged according to their sphere of use. However, one has to be careful when trying to narrow a loanword down to a particular period, and Miller puts considerable emphasis upon (re)borrowing, which "occurred over the course of a millennium" (p. 53), as in the case of, for instance, sponge (p. 68). This chapter ends with a succinct appendix offering an overview of Latin and pre-Old English sound changes.

Chapter 5 is dedicated to the Scandinavian legacy of the English language. It begins with a discussion of the history of Scandinavians in England, from the Viking raids in c. 8 to complete assimilation to the English in c. 12. The account that follows traces Scandinavian influence on toponyms, the lexicon, phonology, morphology, and syntax. Norse-derived words have considerably enriched the English language, even though the types of contact between Scandinavians and the English seem to be different, depending on the area and period. Miller believes that the initial borrowings are the result of adult contact, whereas the later loans testify to bilingualism and code-switching (p. 106). The profound lexical influence also led to some phonological differences between southern and northeastern English; depalatalization of native palatals in the northeast is a case in point, for instance, native church and Danelaw kirk(e) (p. 121). As for the morphological influence, Miller attributes the following changes to Scandinavian-English contact: the borrowing of the pronoun they, the diffusion of the northern present participle -and(e), and the generalization of nominal -ing to participles. Moreover, East Norse (in particular, early Jutland Danish) and English share a number of morphosyntactic innovations, such as noun plural and genitive singular -(e)s, phrasal genitive, reflexive (-)self, omission of the conjunction that, relative ellipsis, preposition stranding with pronominal whwords, preposition stranded passives, adoption of V2 order in the north, and the shift from SOV to SVO. "The fact that Scandinavian and English were closely related provided for a higher degree of hybridization than occurs with more distantly related languages or dialects," concludes Miller (p. 147).

Chapter 6 examines French influence on English, which, according to Miller, was mostly lexical. He criticizes the traditional view that loanwords from Central French followed those from Norman French and agrees with William Rothwell's assertion (1996, 1998) that the division between these two periods is rather artificial (p. 150), for central and northern forms often coexist in one text. Furthermore, due to the imperfect learning of French, an insular variety, Anglo-French, appeared. Loans after the conquest easily fall into groups according to cultural domains (for instance, titles of nobility, law, government, religion) and reflect borrowing from a superstrate; however, "one must distinguish terms superimposed by the Norman conquerors... from the later borrowings that reflect cultural prestige" (p. 167). It is particularly noteworthy that Miller pays special attention to the literary and stylistic status of French words in English texts (pp. 162-164), a topic that rarely comes under careful scrutiny. The period of continued bilingualism was followed by the gradual decline and death of AngloFrench c. 1400, which correlates with "the increase (by double) of French suffixes in English hybrids” (p. 176). Therefore, English was left with a large number of derivational affixes. Whereas the morphological legacy of French is described in great detail (pp. 176-184), the discussion of French impact on English syntax is rather brief (pp. 185-187), as Miller believes that the influence is "very limited" (p. 185). The appendix to this chapter 
presents an overview of major sound changes from Latin to French.

The title of Chapter 7, which deals with later Latin and Greek influences, is "Continuity and revival of classical learning". Therefore, the first part of this chapter is dedicated to the emergence of a liberal arts education, the works of influential Christian writers of c. 2-8, and the history of Latin in the Middle Ages, though the latter account slightly overlaps with the previous sections of the book. The second part of the chapter covers the Middle English period, the humanistic movement, and the Renaissance (c. 13001600 ) as the peak period for latinisms. A detailed survey of Latin and Greek influence on English word formation is offered towards the end of this chapter. All in all, Miller argues that the legacy of Greek and Latin is restricted only to the lexicon and word formation (pp. 219, 221-223).

The final chapter, "External linguistic input to English", summarizes the main argument of the book: 1) French borrowings reflect "a substratal situation in which English borrowed heavily from the dominant language" (p. 228). Furthermore, French, Latin and Greek influence is restricted to the lexicon and morphology; 2) the contact with Scandinavian was mixed, leading to a considerable number of loanwords, whereas the contact with Celtic was substratal. However, "for both, the major influence has been structural" (p. 232). Miller also raises some remaining problems and identifies areas that are understudied, such as the loss of gender in English, acknowledging the need for further research. He uses the last page to restate his key point, "A typical family tree of the IndoEuropean languages lists English on a terminal node in the Germanic subfamily, which is really relevant only for Old English. Syntactically, morphologically, and lexically, Modern English reflects multiple input languages" (p. 236).

Overall, Miller's account is quite consistent and systematic. As his book puts together the bulk of recent studies in etymology, linguistics, archeology, history, and genetics, one should acknowledge the mere body of scholarship that he takes into consideration while discussing a myriad of phonological, lexical, morphological and syntactical influences. Furthermore, far from being just a summary of previous research, the consistent application of Trudgill's theory of sociolinguistic typology even to some frequently disputed or obscure cases, as well as the sharp focus on external impact, make his work a notable contribution to current studies on English historical linguistics.

However, a book that has to tackle such a vast and complex subject is bound to contain a few irrelevant details. Occasionally, random associations, which are due to the sheer vastness of the topic, lead the author astray and confuse the reader, as the above-mentioned borrowings from Germanic and Celtic in Chapter 1 that fall beyond the time scale of the present study, or a rather redundant list of the Church Fathers in Chapter 8. There is also a slight degree of overlap in the chapters discussing classical background to English (Chapters 2, 3, 7).

On the other hand, while Miller's account is accurate and detailed, a few items are noticeably missing. For instance, one component that seems to be lacking from Chapter 2 is a discussion of possible Celtic influences on English phonology, though several studies have recently addressed this issue (Laker, 2009; Minkova, 2011). Another example is the case of Old English cirica from Greek kuriakon. Though Miller uses this loanword as an illustration a number of times (pp. 45, 81, 121), never does he mention the later form cyrice that was probably a learned reborrowing. Furthermore, whereas a number of Latin and French suffixes are being described in great detail, -or of agent-nouns is only mentioned in passing (p. 174). A final instance of such omissions occurs when Miller discusses the later Latin and Greek influence, which he believes to be lexical only, and overlooks the fact that some borrowings are not fully morphosyntactically integrated and preserve their original plurals (Nevalainen, 1999, p. 366).

Besides, Miller makes several claims that are quite controversial. He notes, for instance, that pre-Christian oral works, such as "Beowulf", were written down in c. $7 / 8$ (p. 47). However, there is no consensus view on the issue in recent scholarship (Bjork \& Obermeier, 1997, pp. 18-28). Kevin Kiernan (1996) in particular has argued for a late date for the poem, claiming that "the last poet of 'Beowulf' was the second scribe" (p. 278). Indeed, whether epic poetry could be among the first texts to be written down in Christian monasteries seems rather doubtful.

Miller also suggests that /a/ in such words as man, bank, land, is due to Scandinavian influence (pp. 119120). However, Middle English dialect maps (see "MAN: mon type" in eLALME) clearly demonstrate that the /o/ vowel was restricted to the West Midlands, whereas the /a/ vowel was present outside the ScandinavianEnglish contact area, which does not support Miller's hypothesis.

The book is systematically structured, concise and quite easy to read. All chapters are divided into subsections according to the topic, and most of them have both introductions and conclusions; as a result, the text is not difficult to follow. The appendices are handy and to the point. On the other hand, the book could benefit from a more elaborate word index, divided into subsections to include not only Modern English, but also Old and Middle English words as well as those of Celtic, Latin, Greek, Scandinavian, and French origin.

To conclude, Miller's comprehensive account of external influences will make a highly useful resource for both academics and advanced students of the 
history of the English language. Even though for the most part it requires a solid background in English historical linguistics, even interested laypersons have something to gain by leafing through this illuminating volume.

\section{References}

Benskin, M., Laing, M., Karaiskos, V., \& Williamson, K. (2013). An electronic version of a linguistic atlas of late Mediaeval English. Retrieved from http:// www.lel.ed.ac.uk/ihd/elalme/elalme.html

Bjork, R. E., \& Obermeier, A. (1997). Date, provenance, author, audience. In R. E. Bjork \& J. D. Niles (Eds.), A Beowulf handbook (pp. 13-34). Lincoln, NE: University of Nebraska Press.

Kiernan, K. S. (1996). Beowulf and the Beowulf manuscript. Ann Arbor, MI: University of Michigan Press.

Laker, S. (2009). An explanation for the early phonemicisation of a voice contrast in English fricatives. English Language and Linguistics, 13(2),
213-226.

Minkova, D. (2011). Phonemically contrastive fricatives in Old English? English Language and Linguistics, 15(1), 31-59.

Nevalainen, T. (1999). Early modern English lexis and semantics. In R. Lass (Ed.), The Cambridge history of the English language (Vol. 3, pp. 332-458). Cambridge, UK: Cambridge University Press.

Trudgill, P. (2010a). Contact and sociolinguistic typology. In R. Hickey (Ed.), The handbook of language contact (pp. 299-319). Oxford, UK: John Wiley \& Sons.

Trudgill, P. (2010b). Investigations in sociohistorical linguistics: Stories of colonisation and contact. Cambridge, UK: Cambridge University Press.

Trudgill, P. (2011). A tale of two copulas: LanguageContact speculations on first-millennium England. NOWELE, 62/63, 285-320.

Rothwell, W. (1996). Playing 'follow my leader' in Anglo-Norman studies. Journal of French Language Studies, 6(2), 177-210.

Rothwell, W. (1998). Arrivals and departures: The adoption of French terminology into middle English. English Studies, 79(2), 144-165. 